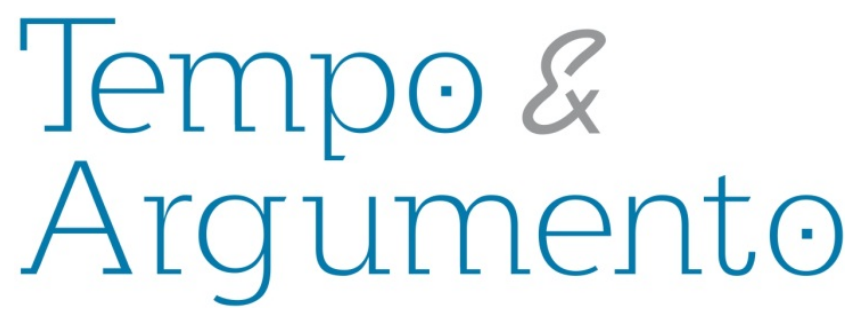

\title{
Acessibilidade documental e autoridade compartilhada: pela construção de uma história pública
}

\begin{abstract}
Resumo
Focalizando a temática mais ampla acerca de abusos do esquecimento provocados por narrativas oficiais locais e, consequentemente, sobre a implicação disso em relação ao ofício dos historiadores e historiadoras, este artigo perscruta caminhos que reflitam sobre a construção de narrativas históricas que levem em conta a participação cidadã no seu processo de realização e divulgação. Para isso, o texto está dividido em duas partes. Inicialmente, a informação sobre a exígua quantidade de arquivos públicos municipais no Brasil é objeto de apreciação levando em conta tanto a legislação nacional que advoga pela acessibilidade, proteção e gestão pública documental, como as dificuldades e carências em relação à institucionalização e à manutenção de arquivos municipais, e também as orientações normativas e ações desenvolvidas pelo CONARQ no intuito de fomentar a implementação destas instituições. Num segundo momento, a discussão em torno dos esquecimentos e ocultamentos propiciados por narrativas oficiais locais é abordada em relação a um específico município do estado do Rio Grande do Sul, possibilitando a reflexão acerca da construção de narrativas locais que observem o princípio de uma autoridade compartilhada. Desenha-se, assim, uma análise que leva em consideração uma história pública em que historiadoras e historiadores contem com a atuação colaborativa de agentes locais que possam problematizar e recobrar vestígios sobre o passado obliterados por mecanismos públicos que, no tempo presente, intentam agir como vetores de uma determinada memória.
\end{abstract}

\author{
Bibiana Werle \\ Doutoranda no Programa de Pós Graduação em \\ História da Universidade do Estado de Santa \\ Catarina. Professora colaboradora do curso de \\ História da Universidade do Estado de Santa \\ Catarina. \\ Florianópolis, Santa Catarina - BRASIL \\ bibiwerle@gmail.com
}

Palavras-chave: Arquivos Municipais. História Local. Documentos Públicos.

\section{Para citar este artigo:}

WERLE, Bibiana. Acessibilidade documental e autoridade compartilhada: pela construção de uma história pública. Revista Tempo e Argumento, Florianópolis, v. 9, n. 21, p. 429 - 449.

maio/ago. 2017.

DOI: $10.5965 / 2175180309212017429$

http://dx.doi.org/10.5965/2175180309212017429 


\title{
Document accessibility and shared authority: for the construction of public history
}

\begin{abstract}
Focusing on the broader theme as regards abuse of forgetfulness caused by local official narratives and, consequently, on its implication in relation to the craft of historians, this article scrutinizes paths that reflect on the construction of historical narratives that take into account civic engagement in their accomplishment and dissemination process. In order to do so, the text is divided into two parts. Initially, information on the meager amount of municipal public archives in Brazil is analyzed taking into account both the national legislation that advocates for accessibility, protection and public management of documents, the difficulties and deficiencies in relation to the institutionalization and maintenance of municipal archives, and also the normative guidelines and actions developed by CONARQ in order to promote the implementation of these institutions. Secondly, the discussion around the oversights and concealments propitiated by local official narratives is addressed in relation to a specific municipality of the state of Rio Grande do Sul, allowing reflection on the construction of local narratives that comply with the principle of shared authority. Thus arises an analysis that takes into consideration public history in which historians count on the collaborative work of local agents who can discuss and recover traces of the past obliterated by public mechanisms which, in the present time, attempt to act as vectors of a particular memory.
\end{abstract}

Keywords: Municipal Archives. Local History. Public Documents. 


\section{Introdução}

A construção de uma história pública passa pela questão da acessibilidade documental. Direito dos cidadãos e cidadãs, dever do poder público, o acesso aos documentos públicos e às informações contidas neles é também acompanhado pela legislação que versa sobre a gestão e a proteção especial a documentos de arquivos. A discrepância entre um conjunto de leis que remete a instituições custodiadoras de acervos documentais de consulta irrestrita e de suas ações efetivas pelos entes públicos, no entanto, se desdobra em espaços de salvaguarda muitas vezes negligenciados, ou mesmo fora do alvo de políticas públicas de âmbito local, como especificamos neste artigo.

Considerando os arquivos municipais como instituições que tornam o acesso à documentação pública local democratizado e, assim, podem servir como ponto de partida para a construção de histórias locais, objetivamos problematizar as narrativas oficiais forjadas em municípios que, muitas vezes, em função de interesses políticos, econômicos e turísticos, ocultam episódios e agentes formadores da história local, sonegando passados e inventando presentes. Neste sentido, esta reflexão analisa, inicialmente, os aparatos legais que regulam o acesso à informação pública e os arquivos municipais. Num segundo momento, a construção de narrativas oficiais é problematizada através de uma pesquisa realizada em um específico município do Rio Grande do Sul, chamado Estrela. Obedecendo ao princípio de construção de uma história através de uma autoridade compartilhada, nos direcionamos para a discussão acerca da atuação colaborativa entre agentes locais e historiadores e historiadoras que buscam uma história pública que leve em conta a participação popular em seu processo de elaboração e divulgação.

\section{Arquivos municipais: aparatos legais}

Em O Vendedor de Passados, filme brasileiro lançado em 2015, o personagem Vicente, interpretado por Lázaro Ramos, afirma que "O passado é tudo aquilo que você lembra, imagina que se lembra, se convence que lembra ou finge que se lembra". 
Baseado no romance homônimo ${ }^{1}$ do escritor angolano José Eduardo Agualusa ${ }^{2}$ (2004), no qual a relação entre os personagens Félix Ventura - alfarrabista e vendedor de passados e a lagartixa Eulálio se constitui em uma metáfora para abordar os usos do passado pela nova elite angolana após a independência do país ${ }^{3}$, o filme brasileiro retoma o mote das implicações e abusos que a simples invenção de um passado sem referencial algum, seja para uma pessoa, seja para um povoado, pode acarretar. Defendendo a dimensão inventada e imaginada do passado na afirmação acima citada, o alfarrabista Vicente se sustenta a partir de seu trabalho como vendedor de passados criados por ele (a partir de uma espécie de "decoupagem" com fotos, cartas, diários, jornais...), a fim de atender aos anseios de clientes que procuram por uma história diferente daquela que realmente vivenciaram.

O caráter da invenção e dos diferentes discursos elaborados sobre o passado é uma das questões centrais deste texto, que busca, para além desta problemática, refletir sobre as implicações que esta situação acarreta para o ofício de historiadores e para a construção de narrativas oficiais num âmbito público local. Neste sentido, a discussão acerca da (in)existência de espaços de salvaguarda documental, como os arquivos públicos municipais - caso especificado neste artigo - é fundamental para nossa discussão, afinal, como aponta Bloch (2001, p. 83):

A despeito do que às vezes parecem imaginar os iniciantes, os documentos não surgem, aqui ou ali, por efeito [de não se sabe] qual misterioso decreto dos deuses. Sua presença ou ausência em tais arquivos, em tal biblioteca, em tal solo deriva de causas humanas que não escapam de modo algum à análise, e os problemas que sua transmissão coloca, longe de terem apenas o alcance de exercícios de técnicos, tocam eles mesmos no mais íntimo da vida do passado, pois o que se encontra assim posto em jogo é nada menos do que a passagem da lembrança através das gerações.

O filme brasileiro foi inspirado no romance "O Vendedor de Passados", escrito por José Eduardo Agualusa e lançado em 2004.

2 Nascido em 1960, José Eduardo Agualusa vivenciou o momento marcado pela guerra de independência angolana e, consequentemente, as tragédias dela decorrentes. A miséria, a corrupção e as disputas pelo poder pelas facções locais são temáticas que pautam sua escrita.

3 Com a recorrente ideia de questionar e problematizar os usos, no presente, de um passado marcado pela dominação portuguesa no território angolano, Agualusa enfoca identidades forjadas por um vendedor de passados (o personagem Félix Ventura) para satisfazer clientes dispostos a se engajarem num novo contexto político que o país, agora independente, demandava. Descender dos "heróis" nacionais era um passado que, viabilizado pelo trabalho de Ventura, concedia credibilidade àqueles que buscavam se afirmar nas lutas políticas daquele presente. 
Referenciais para a construção de uma memória social e, consequentemente, de elaborações identitárias locais, os arquivos - sejam públicos ou privados - são também espaços-chave para o ofício de grande parte dos historiadores e historiadoras. Uma grande dificuldade encontrada em nosso métier, no entanto, ocorre quando essas instituições não podem ser acessíveis, simplesmente pelo fato de inexistirem. Negando o princípio básico da Constituição Federal de 1988, em seu artigo $5^{\circ}$ e inciso XXXIII, de que

todos têm direito a receber dos órgãos públicos informações de seu interesse particular, ou de interesse coletivo ou geral, que serão prestadas no prazo da lei, sob pena de responsabilidade, ressalvadas aquelas cujo sigilo seja imprescindível à segurança da sociedade e do Estado.

A não institucionalização de arquivos públicos municipais demonstra também o descaso e a irresponsabilidade dos órgãos públicos e seus agentes para com a salvaguarda dos documentos historicamente produzidos em cada localidade. De acordo com uma matéria veiculada no site da Empresa Brasil de Comunicação $(E B C)^{4}$, em dezembro de 2014, e reproduzida na página eletrônica do Arquivo Nacional do Ministério da Justiça ${ }^{5}$, dos 5.570 municípios brasileiros, apenas três por cento deles possui um espaço adequado para a guarda de documentos. A posição do Conselho Nacional de Arquivos (CONARQ) $)^{6}$, vinculado ao Arquivo Nacional, denota a preocupação decorrente deste fato, em sua página oficial:

A inexistência de um programa de gestão de documentos e informações de forma integrada tem como consequência grave a perda, o extravio ou a destruição indiscriminada do patrimônio documental público, podendo acarretar danos irreparáveis à administração pública, ao direito fundamental dos cidadãos de acesso aos documentos públicos e às

4 Empresa Brasil de Comunicação S/A, "Governo quer estimular criação de arquivos municipais em todo o país”, matéria disponibilizada em: <http://agenciabrasil.ebc.com.br/cultura/noticia/2014-12/governo-querestimular-criacao-de-arquivos-municipais-em-todo-o-pais>. Acesso em 06 set. 2016.

5 Arquivo Nacional, "Governo quer estimular criação de arquivos municipais em todo o país", matéria disponibilizada em: <http:/www.arquivonacional.gov.br/cgi/cgilua.exe/sys/start.htm? infoid=2224\&sid=119>. Acesso em 06 set. 2016.

6 Criado pelo artigo 26 da Lei $n^{\circ} 8.159$, de 8 de janeiro de 1991, o CONARQ tem, “[...] por finalidade definir a política nacional de arquivos públicos e privados, bem como exercer orientação normativa visando à gestão documental e à proteção especial aos documentos de arquivo", de acordo com o artigo $1^{\circ}$ do Decreto $\mathrm{n}^{\circ} 4.073$, de 3 de janeiro de 2002. 
informações neles contidas, ao direito à história e à memória cultural do município e do país. A Lei de Arquivos determina, em seu art. $9^{\circ}$, que a eliminação de documentos produzidos por instituições públicas e de caráter público, no âmbito do município, será realizada mediante autorização da instituição arquivística pública, na sua específica esfera de competência. Desta forma, a ausência do arquivo público municipal, torna vulnerável a Administração, uma vez que a eliminação de documentos públicos municipais se faz em desrespeito à Lei federal de Arquivos ${ }^{7}$.

A referência, no trecho, à Lei de Arquivos, lei federal $n^{\circ}$ 8.159, de 1991, remete a outra esfera do problema que este dispositivo constitucional visa regulamentar: tanto a gestão, como a proteção especial a documentos de arquivos, fica instituída como dever do poder público, em todas suas esferas. Ou seja, condição indispensável para operacionalizar o trabalho sobre o conjunto documental, a gestão de documentos exige recursos fundamentais que racionalizam o processo de constituição dos arquivos. Face a esta questão, cabe atentarmos para mais um dispositivo legal que versa sobre o tratamento das informações públicas: a Lei de Acesso à Informação, n 12.527, de 18 de novembro de 2011, que, ao regulamentar especialmente o artigo $5^{\circ}$, inciso XXXIII, da Constituição Federal, busca garantir o acesso à informação pública, democratizando o acesso à informação no plano legal.

Amparados legalmente no que tange à acessibilidade documental, é necessário, no entanto, levarmos em consideração o dado apontado acima, de que a quantidade de arquivos públicos municipais no país é exígua. Para além disso, ainda, contamos com o fato de que, algumas vezes, estes poucos arquivos que existem são administrados com dificuldades e negligenciados como política pública local:

É [...] impossível garantir convenientemente acesso a algo que não se controla, não se conserva, não se conhece, não se compreende: o adequado tratamento técnico dos conjuntos documentais arquivísticos é condição fundamental de sua acessibilidade. Daí a extrema relevância da

\footnotetext{
Página oficial do CONARQ, "O arquivo público municipal”, informação disponibilizada em: <http://www.conarq.gov.br/campanha/438-o-arquivo-publico-municipal.html>. Acesso 22/04/2016. Esta mesma informação encontra-se no folder da Campanha de Criação e Desenvolvimento de Arquivos Públicos Municipais, intitulado: "Arquivos Públicos Municipais - mais transparência pública, mais informação, mais memória e mais cidadania”, sem data, p. 8, que está disponível no sítio eletrônico da instituição: <http://www.conarq.arquivonacional.gov.br/images/Campanha/Textos/folder_arquivo_ publico_municipal.pdf>. Acesso em 15 set. 2016.
} 
gestão documental; daí, particularmente, a importância dos procedimentos de classificação e avaliação documental, todos supondo sua realização por pessoal preparado para tarefas tão complexas (o que remete, inevitavelmente, à sua qualificação e ao problema da formação dos profissionais de arquivo). [...] (GONÇALVES, 2013, p. 282)

Levando em conta as dificuldades e carências em relação à institucionalização e à manutenção de arquivos municipais apontadas, e com objetivos que visam "sensibilizar" e "informar" autoridades públicas e cidadãos sobre a "[...] importância dos arquivos públicos para a boa governança, construção da memória e preservação da identidade histórica e cultural da comunidade local"8, o CONARQ desenvolveu a Campanha de Criação e Desenvolvimento de Arquivos Públicos Municipais, em 05 de dezembro de 2014. Com a finalidade de "[...] apoiar os municípios brasileiros a tornar a administração pública municipal mais transparente e eficaz, garantindo dessa forma o direito de acesso às informações e servindo como instrumento para o exercício pleno da cidadania." ${ }^{9}$, a Campanha realizada pelo órgão responsável, entre outros pontos, pela orientação normativa em relação aos arquivos, tem como uma de suas principais preocupações a questão da necessidade de implementação de políticas públicas de gestão de documentos por parte dos entes públicos municipais.

Para o cumprimento dos objetivos estabelecidos pela Campanha, O CONARQ desenvolveu um documento explicativo sobre esta em formato de folder, no qual, além de informar as metas estabelecidas pela mesma, discorre sobre a legislação nacional que regulamenta o acesso à informação como dever do Estado e direito do cidadão. 0 documento também elucida funções e finalidades atribuídas a um arquivo municipal, que incluem:

[...] implementar, avaliar e monitorar políticas públicas de gestão de documentos e informações, envolvendo importante conjunto de programas de gestão, tratamento técnico, transferência, recolhimento, preservação, disponibilização e divulgação de documentos e informações

8 Informe sobre a Campanha de Criação e Desenvolvimento de Arquivos Públicos Municipais, na página eletrônica oficial do CONARQ, disponibilizado em: <http://www.conarq.gov.br/campanha/438-o-arquivopublico-municipal.html>. Acesso em 08 set. 2016.

9 Idem. 
produzidos, recebidos e acumulados pelo poder público municipal, em qualquer suporte ou formato ${ }^{10}$.

Ainda no folder, são destacadas a responsabilidade e os deveres dos agentes públicos municipais em relação à institucionalização e à manutenção dos arquivos, ressaltando o fato de que, caso o gestor público infrinja as medidas legais, estará sujeito à responsabilidade penal, civil e administrativa. No que tange à participação do CONARQ neste processo de "sensibilização" dos agentes das entidades municipais à implementação dos arquivos, o documento versa sobre ações cooperativas do órgão e indica instrumentos para auxiliar os municípios no tocante à criação e à institucionalização dos arquivos, como: a disponibilização de publicações (a "cartilha" intitulada "Criação e Desenvolvimento de Arquivos Públicos Municipais: transparência e acesso à informação para o exercício da cidadania"; normas e diretrizes voltadas para a gestão, tratamento técnico, preservação e acesso aos documentos arquivísticos tanto em formato analógico quanto digital; “publicações técnicas”), um "Programa de Institucionalização e implantação de arquivos municipais", orientações técnicas e, por fim, capacitação e treinamento de agentes públicos municipais através de cursos presenciais e a distância, seminários e vídeos educacionais.

Uma série de publicações como "cartilhas", "guias”, “modelos institucionais", "diretrizes" e "recomendações" disponibilizadas no site do CONARQ certamente representa o empenho da instituição na didatização e acessibilidade de informações técnicas necessárias para os gestores municipais iniciarem o processo de constituição dos arquivos locais. A questão que permanece, no entanto é: em que medida essa quantidade de dados técnicos se torna inteligível entre aqueles que são/serão responsabilizados, nos diversos municípios, pela operacionalização desta tarefa? Lembrando, ainda, o despreparo profissional de muitas destas pessoas, que não possuem uma formação específica ou então desejável para atuar nestas instituições. Em que proporção as orientações técnicas, capacitações e seminários anunciados pelo CONARQ são

10 Folder “Arquivos Públicos Municipais - mais transparência pública, mais informação, mais memória e mais cidadania”, sem data, p. 7. Disponível na página eletrônica do CONARQ:

<http://www.conarq.arquivonacional.gov.br/images/Campanha/Textos/folder_arquivo_publico_municip al.pdf>. Acesso em 14 set. 2016. 
efetivamente oferecidos, ou então demandados pelos agentes locais? Não seria necessário, talvez, construir ações de orientação e educação técnica sobre a constituição dos arquivos partindo das deficiências encontradas em cada localidade ${ }^{11}$ Contando com o fato de que a Campanha foi criada recentemente, e que não possuímos dados mais apurados em relação aos seus desdobramentos, muitas das possíveis respostas a estas questões permanecem desconhecidas para nós. Podemos defender, no entanto, que as ações desenvolvidas pelo CONARQ devam ser elaboradas como uma via de mão dupla, em conjunto com os gestores locais - e estes, contando com a participação dos cidadãos neste processo. Como alerta Gonçalves (2013, p. 282),

[...] Garantir o acesso aos documentos públicos de arquivo envolve, consequentemente, fortalecer as instituições arquivísticas públicas: seu papel social deve se tornar mais claro e mais visível, ao mesmo tempo em que elas necessitam ser percebidas socialmente como relevantes e confiáveis (e obviamente fazer jus a essa percepção).

Ao mesmo tempo em que instigam, estas questões provocam especialmente a nós, historiadores e historiadoras, que muitas vezes nos deparamos com a falta de uma gestão municipal de arquivos, com descaso, ou até mesmo com inexistência destas instituições. Contra uma mera "decoupagem" de um passado, forjado apenas com base na imaginação, como fazia Vicente com seus clientes, “[...] a historiografia aborda um passado racionalmente verificável” (KOSELLECK, 2014, p. 267). Neste sentido, espaços onde se reúna, organize e proteja a documentação local, são estritamente necessários

1 Na pesquisa realizada na internet para a escrita deste texto, não foram encontradas ações localizadas do CONARQ em relação à criação de arquivos municipais desde o final de 2014, quando da criação da Campanha de Criação e Desenvolvimento de Arquivos Públicos Municipais, o que não quer dizer que a mesma não tenha sido desenvolvida. No entanto, na seção "Capacitação de Recursos Humanos", no site da instituiçã̃o, foi possível observar a divulgação de dois cursos a distância: um deles promovido, entre outras instituições (documento ilegível), pela Universidade Federal do Rio Grande do Sul (UFRGS) e tendo como público-alvo pontos de cultura, gestores públicos culturais, professores, terapeutas ocupacionais e interessados em geral; e outro promovido pela Controladoria-Geral da União (CGU), em parceria com a Escola Nacional de Administração Pública (Enap), tendo como público-alvo servidores públicos municipais, agente públicos dos três poderes e das três esferas de governo, além de cidadãos em geral. Na seção "Capacitação de Recursos Humanos" do CONARQ, ainda foram encontradas divulgações referentes à aprovação do mestrado profissional em Preservação e Gestão do Patrimônio Cultural das Ciências e da Saúde, pela Casa de Oswaldo Cruz (COC/Fiocruz), além do VIII Encontro do Centro de Documentação e Apoio à Pesquisa Profa. Dra. Anna Maria Martinez Corrêa (CEDAP) da UNESP. Acesso em 22 abr. 2016. 

verdadeiramente inclusivo, contestado, aberto e dialógico [...]” (FRISCH, 2016, p. 61).

\section{Autoridade compartilhada na construção de uma história PÚBLICA}

Para abordar a temática desta segunda parte do texto, que se refere aos abusos públicos sobre um esquecimento possibilitado por narrativas oficiais locais, e também ao ofício dos historiadores e historiadoras na construção de pesquisas que levem em conta a participação cidadã, recorro, novamente, à ficção. Após ter comprado, de Vicente, um passado sem qualquer tipo de vinculação com a sua vivência anterior, Clara, personagem interpretada por Alinne Moraes em O Vendedor de Passados, atrela publicamente sua nova história (por meio de uma falsa autobiografia) a um trauma socialmente compartilhado: a ditadura argentina. A situação toma dimensões que se desdobram em consequências impensáveis por Vicente, quando da criação desse passado, meses antes. Observamos aí um abuso: o uso público, no tempo presente, de um passado inventado com base em um fato ocorrido recentemente e, por isso, tão presente na memória social. Sem intenção de me deter mais longamente sobre o filme, o que nos interessa é o enredo construído em torno da temática dos abusos públicos possibilitados quando não podemos livremente acessar, verificar e comprovar as evidências nas quais nos pautamos para elaborar um discurso sobre o passado.

Caracterizando como uma das singularidades do campo da História do Tempo Presente a ideia de esta residir na "contemporaneidade do não contemporâneo", Dosse (2012, p. 6) aponta para uma importante questão de âmbito temporal: a do "presente do passado incorporado", ou seja, de que nosso presente é construído com base no passado, e o incorpora. Nesse sentido, ao investigar o presente, historiadores atentamse, entre outros fatores, às diversas representações que o passado apresenta nos vestígios examinados neste tempo. Sempre, contudo, ciente dos possíveis lapsos deixados ao longo do período temporal a que se debruça, afinal, a história está cheia de 
lacunas, daquilo que Sarlo (2007, p. 9) chama de “inabordável”. Para refletirmos sobre presentes inventados - ou passados em parte inacessíveis - e, além disso, sobre as implicações que acarretam ao trabalho de historiadores, discorro, a título de exemplo, sobre como essas questões transversalizam uma narrativa oficial constituída publicamente em um munícipio específico do RS, em certa medida.

Localizado na região centro-leste do estado do Rio Grande do Sul e marcado pelo processo colonizatório de imigração alemã por via das colônias particulares que se estabeleceram na região a partir de 1853, (AHLERT; GEDOZ, 2001, p. 50-51), o município de Estrela, em sua relação com as questões aqui abordadas, é o espaço no qual me detenho para esta reflexão. Regionalmente conhecido pelo Festival do Chucrute ${ }^{12}$, pelo campeonato de Jogos Germânicos ${ }^{13}$ e pela fala, de muitos de seus moradores, em dialetos alemães, estas características podem nos passar a impressão de que o município é constituído hegemonicamente pelo elemento cultural germânico. Considerando as comemorações municipais e os roteiros turísticos ${ }^{14}$ existentes no município, poderíamos concordar com essa percepção. O depoimento do prefeito municipal a um jornal local, referindo-se aos festejos do aniversário de 157 anos de Estrela, em maio de 2013, por exemplo, reitera esta ideia: “Admiro os estrelenses pela paixão que têm pela cultura germânica. Observar toda essa gente que compareceu para prestigiar a abertura de nossa festa me dá muito orgulho"15. O informativo, que também discorria sobre a

12 Realizado desde o ano de 1965, o Festival do Chucrute de Estrela faz parte dos eventos oficiais de comemoração do aniversário do município. Neste evento se apresenta o conjunto de Grupos de Danças Folclóricas Alemãs de Estrela, o mais antigo conjunto de danças folclóricas alemãs do Brasil, que é sediado no município e mantido, desde 1964, pela Igreja Evangélica de Confissão Luterana do Brasil local.

13 Em 2016, as atividades que compunham os "Jogos Germânicos" foram: Pau de Sebo; Carregar a Tora de Lenha; Serrar e Rachar a Lenha; Carrinho de Mão; Cabo de Guerra; Estafeta Germânica; Galinha Caipira e Pegar Leitão, de acordo com o JORNAL NOVA GERAÇÃO, Especial Estrela 140 anos, 20 mai. 2016, p. 5. Como podemos observar, algumas atividades, como "Cabo de Guerra" não possuem uma origem propriamente germânica, apesar de o nome dos Jogos fazer esta referência.

14 Chegando ao município, o visitante que tiver interesse em participar de algum trajeto turístico pela região, encontra no "Roteiro Delícias da Colônia" - criado em 2002 pela Secretaria de Cultura e Turismo de Estrela, em parceria com proprietários e empreendedores locais, com a empresa de viagens e turismo Imitur, e os poderes públicos municipais das cidades partícipes do roteiro - outras referências à colonização alemã da região. Passando por pontos como a "Casa do Artesão e Produtos Coloniais", o "Convento Franciscano São Boaventura", o "Recanto do Avestruz", a "Sirlei Chocolates", o "Cactário Horst" e o "Alambique Berwanger", o visitante entra em contato com produtos coloniais e construções que remetem, de acordo com o folder do Roteiro, à imigração alemã.

15 “Começa a Maifest dos 137 anos". O Informativo do Vale, ano XLII, p. 4, 18 e 19 maio 2013. 
programação do evento, anunciava: “Até o dia 26, a cultura alemã seguirá sendo cultuada por meio de músicas, dança e gastronomia típica"16 - ou seja: buscando vincular sua história a um passado que remonta à colonização germânica na região através destes eventos e circuitos turísticos, essa valorização de uma suposta cultura alemã também alia interesses econômicos e políticos na constante elaboração de uma identificação étnica em detrimento de outras, que também compõem a formação social do município.

Esse discurso de passado heroico (pois a imagem do colono alemão como desbravador e responsável pelo progresso local acompanha estas festividades) que se manifesta num presente aparentemente desprovido de tensões, consensual e harmonicamente promovido pelo poder público municipal deve ser, todavia, problematizado por historiadores e pode ser motivo de contestação de grupos sociais considerados alijados do discurso oficialmente elaborado. É justamente pelos usos aos quais os eventos e comemorações estão sujeitas que, conforme Ricoeur (2007, p. 98-104), podem ocorrer abusos da memória ou, no caso, do esquecimento. Qual, ou quais passados estão ofuscados por essa coesão social propagada no presente? A existência de um arquivo público municipal, que oportunizasse a construção de uma história local racionalmente verificável, certamente poderia preservar fontes que fornecessem indícios para ajudar a responder a questão, que se torna, todavia, impraticável, pois Estrela faz parte dos 97 por cento de municípios sem arquivos históricos municipais no Brasil.

Impraticável a pesquisa no arquivo, impossível a procura de outros locais ou agentes sociais que possam guardar vestígios sobre o passado? Não. Neste sentido, para orientar o início desta busca, a historiografia fornece questões-chave de problematização - por exemplo, neste caso, a referência de que os municípios marcados pela imigração alemã nas regiões sul do Brasil foram alvo da Campanha de Nacionalização varguista. Iniciada a partir do Decreto-Lei 383 assinado por Getúlio Vargas, em abril de 1938, mas intensificada com o alinhamento brasileiro ao grupo Aliado após o afundamento de navios brasileiros e a declaração de guerra entre Brasil e Alemanha em 1942, a Campanha de Nacionalização, tinha como objetivo a difusão de uma versão acerca da identidade nacional brasileira e, entre as ideias que orientaram as ações dos agentes do Estado Novo

16 Idem. 
permite construir fatos -, ele [o historiador] tem uma ideia das fontes e dos documentos que Ihe permitirão resolvê-la, ou seja, também uma primeira ideia do procedimento a adotar para abordá-los".

Sem um arquivo público municipal, mas com as questões a serem problematizadas, historiadores lançam mão de alternativas de pesquisa, como, por exemplo, a história oral. Esta, elemento proficiente para a construção de uma história pública, possibilita o que Michael Frisch (2016, p. 62) chama de "uma autoridade compartilhada”, no sentido de que “[...] na natureza da história oral e da história pública nós não somos a única autoridade, os únicos intérpretes, os únicos autores-historiadores. Em vez disso, o processo de interpretação e de construção de significados é, por definição, compartilhado”. Em Estrela, para pesquisar a Campanha de Nacionalização (WERLE, 2014), foi possível contar com testemunhos que vivenciaram este processo, pois várias crianças e adolescentes que moravam no município na época, hoje lembram os tensos momentos provocados na escola, no mercado, em casa, nas igrejas e bailes por não saberem falar o vernáculo naquele tempo, como afirma o morador Silvino:

Nos dois primeiros anos eu ainda escrevia em alemão, depois vieram as guerras e coisas e aí começaram a proibir. Aí cada um ganhou um livro em tradução, alemão para o português. E eu já escrevia em alemão tudo, e então foi uma coisa pesada. Foi de uma semana pra outra. O delegado daqui era muito rígido na época. Foi uma transição meio rápida. A gente não sabia nada e não podia nem falar em alemão. ${ }^{17}$

Considerando a memória como uma narrativa construída no tempo presente e passível de alterações e flutuações (POLLAK, 1992), a narrativa de Silvino representa a importância dada ao aprendizado da língua nacional para não ser alvo de perseguições naquele período. De acordo com Portelli (2006, p. 111), “[...] tanto fatos quanto

BIRCK, Silvino. Entrevistadora: Bibiana Werle. Estrela, 2010. Cassete sonoro. Entrevista concedida para o Projeto de pesquisa "A Campanha de Nacionalização e sua Memória no Alto Taquari (RS)". Acervo da autora. 
Fundamental, apesar disso, é conhecermos os fatos para cruzarmos às representações e, daí, tentarmos compreender, com aporte teórico, o porquê de ser representado daquela forma. Para além das narrativas elaboradas por moradores de Estrela no presente, esses testemunhos podem, ainda, oportunizar outras formas de acessar e verificar um passado marcado por dissenções ocultadas nos mecanismos públicos que intentam agir como vetores de memória no tempo presente, como as festividades e os roteiros turísticos.

Ao narrarem e, dessa forma, criarem uma temporalidade que fornecesse sentido ao seu passado, muitas das pessoas entrevistadas procuravam objetos, fotos e documentos sobre o período da campanha nacionalista ${ }^{18}$. Salvo-condutos, cadernos e até cartazes que eram espalhados pelos muros do município (figura 1) traziam à tona novos vestígios para a compreensão daquele passado marcado pela nacionalização forçada. Conforme Cunha (2008, p. 118) “Ao iluminar esses papéis 'ordinários' pode-se pensar na importância de uma memória de papel para o reconhecimento de diferentes práticas, costumes, rituais, ações e sociabilidades como ponto de partida para reinventar outros presentes [...]". Cada material encontrado pelos entrevistados, dessa forma, desdobravase em novas evidências sobre o período do Estado Novo na região.

18 A entrevista de Silvino faz parte de um conjunto de vinte entrevistas realizadas para a construção de minha dissertação de mestrado (WERLE, 2014). Na busca por vestígios acerca da Campanha de Nacionalização em Estrela, as narrativas de antigos moradores da cidade possibilitaram a ampliação da pesquisa, muito dificultada pela falta de um arquivo público municipal na localidade. As entrevistas deram-se através de um movimento de "reação em cadeia", no sentido de que cada entrevistado sugeria outros para testemunharem sobre o período abordado. A utilização da metodologia da História Oral utilizada foi baseada na proposta referenciada por Verena Alberti (2005) para as pesquisas realizadas no Centro de Pesquisa e Documentação de História Contemporânea do Brasil (CPDOC), obedecendo à forma como esta instituição convencionou a maneira de fazer as entrevistas e suas transcrições. 
Figura 1 - Cartaz colocado nos muros do município de Estrela proibindo o uso dos idiomas alemão, italiano e japonês

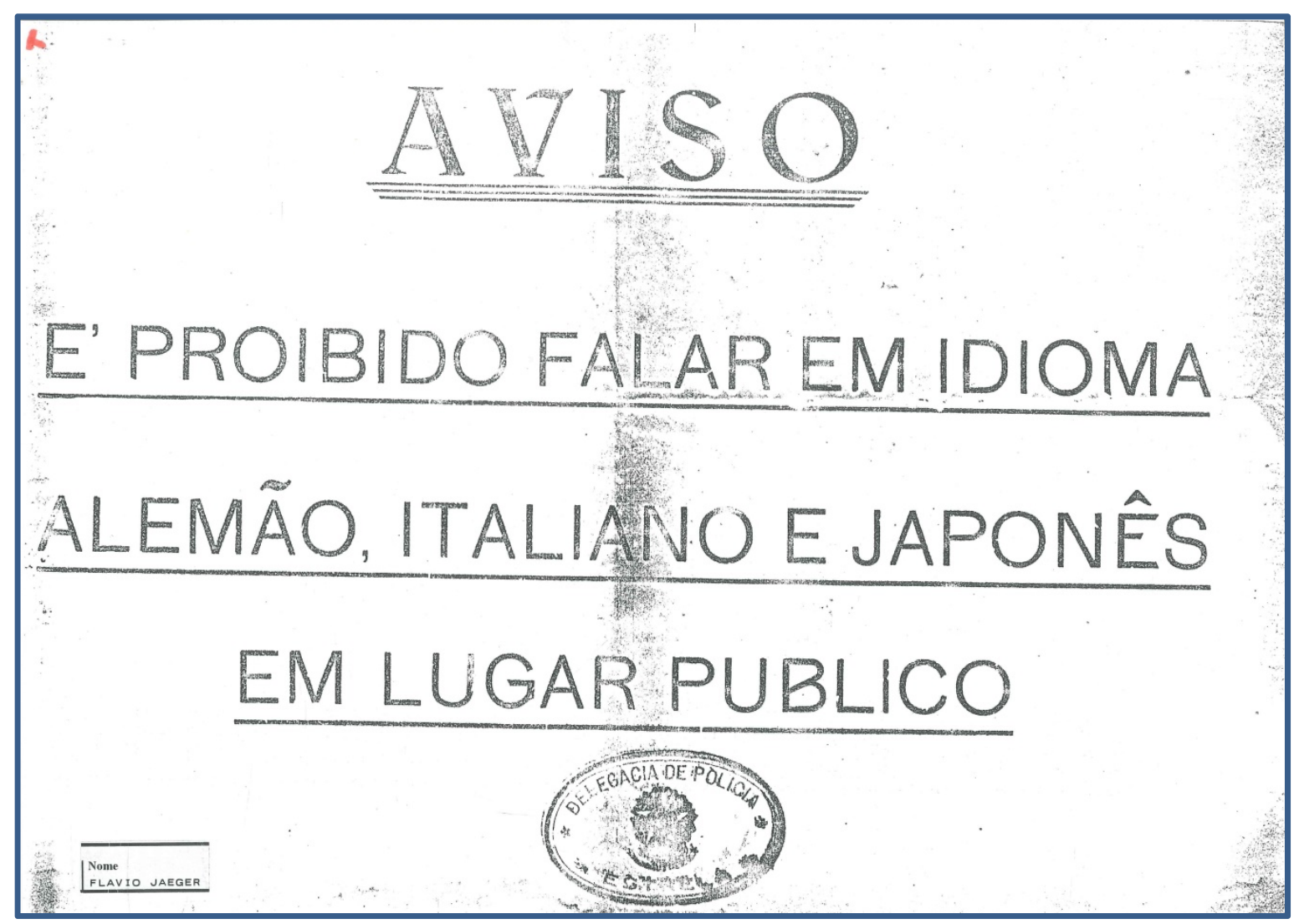

Fonte: Documento cedido por Flávio Jaeger, morador do município de Estrela (RS). Na parte inferior do cartaz consta o carimbo da Delegacia de Polícia do município.

No caso da investigação no município de Estrela, as possibilidades de pesquisa também contaram com a colaboração de um memorialista local. Este, filho do sócio de um jornal da época pesquisada, guarda ainda hoje os exemplares do semanário 0 Paladino $^{19}$. Fonte para analisar diversas questões referentes à campanha nacionalista, como a censura aos meios de comunicação que circulavam em idioma alemão, o jornal não conta, atualmente, com o apoio do poder público para garantir a devida preservação que o semanário deveria receber. Parcerias para uma possível digitalização e manutenção até deram pistas de serem realizadas, mas não se concretizaram. Resulta daí que a

19 Fundado por Antonio Cardoso em setembro de 1921, na cidade de Estrela, o jornal "O Paladino" (que se autodenominava como "o semanário de maior tiragem e circulação no Alto Taquari”) funcionou até o ano de 1941. Com uma tiragem entre mil e mil e quinhentos jornais por edição, "O Paladino" foi um semanário bilíngue que, publicado aos sábados, a cada domingo atingia não apenas o público da área urbana da cidade, mas também as pessoas da zona rural que "iam para a cidade" frequentar as missas dominicais. 
possibilidade de manusear e pesquisar as quatro longas páginas de cada edição de 0 Paladino se torna viável apenas devido à vontade pessoal daqueles que se preocupam com preservação da história local e, também, de suas famílias. Observamos, aí mais um elemento patente na direção de pensarmos uma história pública: a atuação colaborativa, como ressaltam Mauad, Almeida e Santhiago (2016, p. 12), “[...] na qual diferentes agentes produtores trabalham dialogicamente".

Para além do fator colaborativo de cidadãos e cidadãs estrelenses que se mobilizaram para recobrar fontes acerca de um passado, a "sorte" também teve seu lugar na pesquisa. Se, por um lado, a "sorte" é interessante ao surpreender a quem pesquisa com um vestígio inesperado, por outro, remonta à ideia de que, caso o município possuísse um arquivo público organizado, ela poderia se transformar em um registro acessível a todos e, além disso, pudesse impedir um possível descarte de determinado vestígio. Com as fontes encontradas na Igreja Evangélica de Confissão Luterana de Estrela, por exemplo, o que sucedeu remete à máxima: “estar no lugar certo, na hora certa". Cerca de cinco pilhas de documentos aleatórios e recentemente depositados no corredor da instituição tinham dois destinos possíveis: o descarte, ou o envio para alguma outra instância dentro da igreja. Para a pesquisa sobre a fiscalização e os cuidados que os pastores e fiéis deveriam manter durante o período em que "era proibido falar em alemão", a oportunidade de pesquisar a documentação trouxe à tona materiais (cartas, correspondências, atas, fonogramas...) que permitiram uma análise bastante profunda acerca das relações eclesiásticas locais.

Retomando Bloch (2001, p. 83), os documentos certamente não aparecem aqui ou ali por um misterioso decreto dos deuses, mas sim como desdobramento de ações humanas historicamente situadas. No caso do município abordado, os documentos fornecidos pela população local possibilitaram o acesso a fontes públicas que estavam restritas ao âmbito privado e demonstraram como a participação cidadã é significativa no processo de compreensão e problematização da história ao revelar tensões ocultadas seja pelas comemorações públicas que enaltecem uma versão identitária, seja pela inexistência de arquivos públicos que possibilitem o acesso a fontes de um passado tão presente. Para algumas das pessoas que visualizavam o chamado "desfile típico" que 
abre o Festival do Chucrute preencher as ruas do município com uma narrativa glorificada e harmônica sobre o passado, talvez a pesquisa possa ter recobrado memórias antes guardadas para o espaço privado daqueles que vivenciaram um período marcado pela dor. Ou então, ao menos pode ter suscitado a interrogação de moradores locais para uma narrativa que, além de heroicizada em torno do imigrante alemão, é exclusivista, pois oblitera a diversidade étnica que compõe a localidade.

\section{Considerações finais}

Depender de "acasos", da "sorte" e de ações de "salvamento" de documentos públicos prestes a serem descartados não deveria se constituir em uma prática do trabalho de historiadores e, de maneira alguma, traz benefícios às instituições locais. Pelo contrário, o depósito de documentos em "salinhas" vagas, em gavetas e armários trancados, ou ainda encaixotados em algum canto qualquer das instituições nega, por um lado, um direito básico dos cidadãos e cidadãs - de receber, dos órgãos públicos informações de seu interesse particular, ou coletivo, como previsto na Constituição Federal - e oculta, por outro lado, possíveis escritas sobre passado pelos historiadores e historiadoras. Estas poderiam tornar visíveis registros acerca do passado para e em colaboração com a população e, talvez, ajudar a evitar abusos provocados por um esquecimento, por um ocultamento - muitas vezes nada ingênuo - de informações de caráter público.

Não é pretensão afirmar aqui, também, que a existência de arquivos municipais evite qualquer tipo de esquecimentos. Meramente existir, sem fazer parte do cotidiano da população e sem ser percebido como relevante socialmente, não garante a funcionalidade do arquivo. A preocupação com a preservação, com um programa de gestão documental e de informações de maneira integrada, o preparo de pessoal qualificado e a disponibilização de documentos e informações são responsabilidades do poder púbico, e a ele cabe realizar este processo de maneira a incluir a sociedade.

Como afirma Albuquerque Júnior (2012, p. 65), “Os historiadores, embora não deixem de ser, hoje, vendedores de passado, quase sempre a preço vil, devem fazê-lo não 

passar pela democratização do acesso à informação historicamente construída, se efetiva com a colaboração dos agentes sociais na construção das narrativas sobre o passado, no sentido de uma autoridade compartilhada, atravessando "o abismo entre a torre de marfim e o mundo real"20. Cabe a uma história pública ser "agente do luto social", problematizando os pontos de cristalização das memórias, analisando suas funções políticas, os significados atribuídos a eles ao longo do tempo, assim como os agentes sociais e institucionais envolvidos em sua constante elaboração. Perscrutar estes aspectos muda o foco de um enaltecimento para um estranhamento que ajude a revelar os dissensos encobertos pela falsa impressão de que exista uma harmonia consensual nos mesmos.

\section{Referências}

AGUALUSA, José Eduardo. O vendedor de passados. Rio de Janeiro: Gryphus, 2004.

AHLERT, Lucildo; GEDOZ, Sirlei Terezinha. Povoamento e desenvolvimento econômico na região do Vale do Taquari, Rio Grande do Sul - 1822 a 1930. Estudo e Debate. Lajeado, ano 8, n. 1, p. 49-91, 2001.

ALBERTI, Verena. Manual de história oral. $3^{\circ}$ ed. Rio de Janeiro: Ed. FGV, 2005.

ALBUQUERQUE JÚNIOR, Durval Muniz. As sombras brancas: trauma, esquecimento e usos do passado. In: VARELA, Flávia; MOLLO; Helena Miranda; PEREIRA, Mateus Henrique de Faria; MATA, Sérgio da. (Orgs.). Tempo Presente \& Usos do Passado. Rio de Janeiro: Ed. da FGV, 2012. p. 51-66.

20 Referência ao anúncio de um cartaz sobre congresso de história pública do Ruskin College (LIDDINGTON, 2011, p. 42). 
BLOCH, Marc. Apologia da história, ou, o ofício de historiador. Rio de Janeiro: Jorge Zahar, 2001.

BRASIL. Constituição (1988). Portal da Presidência da República. Brasília, DF: [s.n.], 2016. Disponível em: <http://www2.planalto.gov.br/acervo/constituicao-federal>. Acesso em: 15 set. 2016.

BRASIL. Decreto-Lei 383, de 18 de abril de 1938. Veda a estrangeiros a atividade política no Brasil e dá outras providências. [Portal Legislação da Câmara dos Deputados]. Brasília, DF: [s.n.], 2016. Disponível em: <http://www2.camara.leg.br/legin/fed/declei/19301939/decreto-lei-383-18-abril-1938-350781-publicacaooriginal-1-pe.html>. Acesso em: 5 set. 2016.

BRASIL. Lei 8.159, de 9 de janeiro de 1991. Dispõe sobre a política nacional de arquivos públicos e privados e dá outras providências. Portal da Presidência da República. Brasília, DF: [s.n.], 2016. Disponível em: <http://www.planalto.gov.br/ccivil_03/leis/L8159.htm>. Acesso em: 15 set. 2016.

BRASIL. Lei 12.527, de 18 de novembro de 2011. Regula o acesso a informações previsto no inciso XXXIII do art. 50, no inciso II do § 30 do art. 37 e no § 20 do art. 216 da Constituição Federal; altera a Lei no 8.112, de 11 de dezembro de 1990; revoga a Lei no 11.111, de 5 de maio de 2005, e dispositivos da Lei no 8.159, de 8 de janeiro de 1991; e dá outras providências. Portal da Presidência da República. Brasília, DF: [s.n.], 2016. Disponível em: <http://www.planalto.gov.br/ccivil_03/_ato2011-2014/2011/lei/l12527.htm>. Acesso em: 10 set. 2016.

CUNHA, Maria Teresa Santos. Essa coisa de guardar... homens de letras e acervos pessoais. História da Educação. Pelotas: UFPel, v. 12, p. 109-130, 2008.

DOSSE, François. História do tempo presente e historiografia. Tempo \& Argumento. Florianópolis, v. 4, n. 1, p. 5-22, jan./jun. 2012.

FRISCH, Michael. A história pública não é uma via de mão única ou De A Shared Authority à cozinha digital, e vice-versa. In: MAUAD, Ana Maria, ALMEIDA, Juniele Rabêlo de, SANTHIAGO, Ricardo (Orgs.). História pública no Brasil - sentidos e itinerários. São Paulo: Letra e Voz, 2016. p. 57-71.

GONÇALVES, Janice. A recusa do segredo: exercício de direitos e acesso a documentos públicos. Tempo \& Argumento, v. 5, p. 266-287, 2013.

KOSELLECK, Reinhart. Estratos do Tempo: estudos sobre História. Rio de Janeiro, RJ: Contraponto, 2014. 
LIDDINGTON, Jill. O que é história pública? In: ALMEIDA, Juniele Rabêlo de; ROVAI, Marta Gouveia de Oliveira (Orgs.). Introdução à história pública. São Paulo: Letra e Voz, 2011. p. 31-52

MAUAD, Ana Maria; ALMEIDA, Juniele Rabêlo de; SANTHIAGO, Ricardo. Introdução. In: MAUAD, Ana Maria; ALMEIDA, Juniele Rabêlo de; SANTHIAGO, Ricardo. História pública no Brasil:sentidos e itinerários. São Paulo: Letra e Voz, 2016. p. 11-20.

POLLAK, Michael. Memória e identidade social. Estudos Históricos. Rio de Janeiro, v. 5, n. 10, p. 200-212, 1992.

PORTELLI, Alessandro. O massacre de Civittela Val diChiana (Toscana, 29 de junho de 1944): mito e política, luto e senso comum. In: FERREIRA, Marieta de Moraes e AMADO, Janaína (Orgs.). Usos \& abusos da história oral. Rio de Janeiro: FGV, 2006. p. 103-130.

PROST, Antoine. Doze lições sobre a história. Belo Horizonte: Autêntica, 2008.

RICOEUR, Paul. A memória, a história, o esquecimento. Tradução: Alain François. Campinas, SP: Ed. da UNICAMP, 2007.

SARLO, Beatriz. Tempo passado: cultura da memória e guinada subjetiva. São Paulo: Cia. das Letras, 2007.

O VENDEDOR de passados. Direção e produção: Lula Buarque de Hollanda. Produção: Conspiração Filmes, Imagem Filmes e Teleimage. Ano de produção: 2013. Ano de lançamento: 2015. Duração: 82 minutos. Brasil.

WERLE, Bibiana. A campanha de nacionalização e sua memória no Alto Taquari (RS). Porto Alegre: UFRGS, Dissertação (Licenciatura em História), Universidade Federal do Rio Grande do Sul, 2014. 
Recebido em 30/09/2016 Aprovado em 16/11/2016

Universidade do Estado de Santa Catarina - UDESC

Programa de Pós-Graduação em História - PPGH

Revista Tempo e Argumento

Volume 09 - Número 21 - Ano 2017

tempoeargumento@gmail.com 